\title{
ARE THERE REGIONAL VARIATIONS IN THE PRESENTATION OF CHILDHOOD LEUKEMIA?
}

\author{
Klerize Anecely de Souza Silva ${ }^{1}$, Ciliana Rechenmacher ${ }^{1,3}$, Rahuany \\ Velleda de Morais ${ }^{2,3}$, Mariana Bohns Michalowski ${ }^{1,3}$, Liane Esteves Daudt ${ }^{1}$
}

Clin Biomed Res. 2021;41(3):192-198
1 Programa de Pós-Graduação em
Saúde da Criança e do Adolescente,
Universidade Federal do Rio Grande
do Sul. Porto Alegre, RS, Brasil.

2 Universidade Federal de Ciências da Saúde de Porto Alegre. Porto Alegre, RS, Brasil.

3 Centro de Pesquisa Experimental, Hospital de Clínicas de Porto Alegre. Porto Alegre, RS, Brasil.

Corresponding author: Liane Esteves Daudt Idaudt@hcpa.edu.br Serviço de Hematologia, Hospital de Clínicas de Porto Alegre Rua Ramiro Barcelos, 2350 90035-935, Porto Alegre, RS, Brasil.

\section{ABSTRACT}

Introduction: Treatment of childhood acute lymphoblastic leukemia (ALL) is based on risk stratification. This study aimed to assess the agreement between risk group classifications in the different childhood ALL treatment protocols used in a referral hospital in southern Brazil.

Methods: We retrospectively reviewed the medical records of patients aged 1 to 18 years with B-cell ALL treated at a hospital from January 2013 to April 2017. Agreement between risk classifications was assessed by the kappa coefficient.

Results: Seventy-five patients were analyzed. There was poor agreement between risk stratification by GBTLI 2009 and BFM 95 protocols (kappa $=0.22 ; p=0.003$ ) and by GBTLI 2009 and IC-BFM 2002 protocols (kappa $=0.24 ; p=0.002$ ). Risk group distribution was $13.3 \%$ for low risk, $32.0 \%$ for intermediate risk, and $54.7 \%$ for high risk based on stratification by the GBTLI 2009 protocol, and $28.0 \%$ for low risk, $42.7 \%$ for intermediate risk, and $29.3 \%$ for high risk based on stratification by the IC-BFM 2002 protocol. Overall survival was $68.6 \%$.

Conclusion: This study provides numerous points to ponder about the treatment of leukemia in Brazil. The percentage of patients classified as high risk in our sample was higher than that reported in the international literature. This difference, however, had no impact on overall survival, which was shorter than that reported in the international literature.

Keywords: Childhood ALL; Risk factors; Immunophenotyping; Minimal residual disease

\section{INTRODUCTION}

Leukemia accounts for $30 \%$ of all cancers diagnosed in children younger than 15 years, and $75 \%$ of these cases are diagnosed as acute lymphoblastic leukemia $(A L L){ }^{1}$. As in other childhood cancers, the survival of children and adolescents with ALL has improved significantly over time ${ }^{2}$. The 5 -year survival rate for ALL increased from $60 \%$ to approximately $90 \%$ for children aged $<15$ years and from 28 to $75 \%$ for adolescents aged 15 to 19 years between 1975 and 2010 in the United States ${ }^{3}$.

Much of this improvement is attributable to the tailoring of treatment to the individual characteristics of each patient and of the disease and, more recently, to novel targeted therapies ${ }^{4}$. For decades, groups that study childhood ALL have used risk classification systems to allocate patients to treatment regimens based on their estimated risk of treatment failure. That is, children with favorable clinical and biological features receive less toxic therapy, while more aggressive therapy is reserved for patients who are at higher risk of relapse and less likely to survive in the long term ${ }^{5}$.

This stratification is possible using prognostic factors ${ }^{6}$. Early risk classification systems were based only on clinical factors, such as age and white blood cell count at diagnosis. Current classification systems include the molecular characteristics of leukemic cells at diagnosis and response to treatment. One of the methods used is the detection of minimal residual disease (MRD). Currently, MRD is the most important prognostic factor for 
ALL in children ${ }^{7}$. Early response to chemotherapy, with rapid reduction of leukemic cells, especially at the end of remission induction therapy, is an important indicator of a more favorable outcome and a lower risk of relapse ${ }^{8}$.

In Brazil, most centers treating pediatric patients with ALL base their treatment on the Berlin-FrankfurtMünster (BFM) group protocols or on the Brazilian Cooperative Group for the Treatment of Childhood ALL (Grupo Brasileiro de Tratamento da Leucemia Infantil, GBTLI) protocols. At the hospital, two different protocols were used between 2009 and 2017: treatment suggested by the GBTLI 2009 protocol and treatment regimen proposed by the BFM group.

The present study aimed to describe the clinical and laboratory profile, as well as the outcome of patients with B-cell ALL (B-ALL) treated, and to assess the agreement between risk group classifications in patients classified according to the different childhood ALL treatment protocols or regimens used in the institution.

\section{METHODS}

\section{Study population}

We conducted a descriptive cross-sectional epidemiological study with retrospective data collection of 75 patients aged 1 to 18 years with B-ALL treated from January 2013 to April 2017. All patients were treated in the same hospital during the study period.

The patients' medical records were reviewed for the following data at the time of diagnosis and after initiation of treatment: age; leukocyte count; central nervous system (CNS) involvement; morphology of leukemic cells; immunophenotyping; cytogenetics; molecular biology; MRD by flow cytometry (FCM) and morphology at day 15 (D15) of induction; MRD by FCM and morphology at the end of induction (D33/D35); risk stratification based on the National Cancer Institute $(\mathrm{NCl})$ criteria and on the criteria of the BFM 95, Intercontinental (IC)-BFM 2002, IC-BFM 2009, GBTLI 99, and GBTLI 2009 treatment regimens/protocols (Table 1$)^{9-15}$; occurrence of relapse or death; current patient status; and date of last update.

Table 1: Risk classification according to the $\mathrm{NCl}$ criteria and to the BFM and GBTLI treatment regimens.

\begin{tabular}{|c|c|c|c|}
\hline \multirow{2}{*}{$\begin{array}{l}\mathrm{NCl} \text { criteria and } \\
\text { treatment regimens }\end{array}$} & \multicolumn{3}{|c|}{ Risk groups } \\
\hline & LR & IR & HR \\
\hline $\mathrm{NCl}$ & $\begin{array}{l}\text { - Leukocytes }<50,000 / \mathrm{mm}^{3} \\
\text { at diagnosis and age }>1 \text { year } \\
\text { and }<10 \text { years }\end{array}$ & & $\begin{array}{l}\text { - Leukocytes }>50,000 / \mathrm{mm}^{3} \text { at } \\
\text { diagnosis and/or age } 110 \text { years }\end{array}$ \\
\hline GBTLI 99 & $\begin{array}{l}\text { - Age > } 1 \text { year and }<9 \text { years; } \\
\text { - Leukocytes }<50,000 / \mathrm{mm}^{3} \text { at } \\
\text { diagnosis and }<5,000 / \mathrm{mm}^{3} \text { in } \\
\text { PB at D8; } \\
\text { - Absence of blasts in PB at } \\
\text { D14 and M1/M2 BM at D14; } \\
\text { - M1 BM at D28; } \\
\text { - Patients classified as LR } \\
\text { who during treatment meet the } \\
\text { requirements for inclusion in the } \\
\text { HR group will change groups. }\end{array}$ & & $\begin{array}{l}\text { - Age }<1 \text { year and } \geq \text { ge }<1 \text { year } \\
\text { and fied as LR who during } 3 \\
\text { at diagnosis; } \\
\text { - Slow response to treatment } \\
\text { (leukocytes } \geq \text { low resp3 at D7 } \\
\text { of induction); } \\
\text { - Presence of blasts in PB } \\
\text { at D14; } \\
-\mathrm{M} 3 \mathrm{BM} \text { at D14 and/or } \\
\text { M2/M3 BM at D28 and/or } \\
\text { evidence of extramedullary } \\
\text { leukemic involvement. }\end{array}$ \\
\hline GBTLI 2009 & 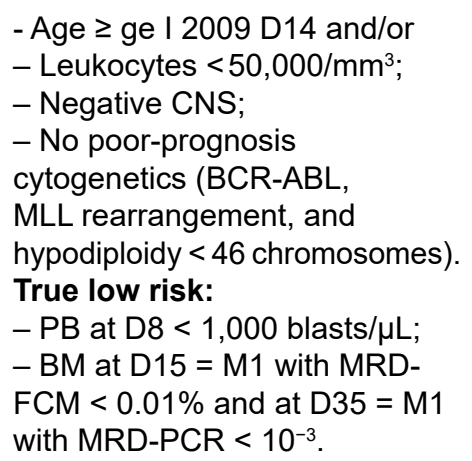 & $\begin{array}{l}\text { PB at D8 }<1,000 \text { blasts } / \mu L ; \\
- \text { BM at D15 = M1/M2 with } \\
\text { MRD-FCM }(00.01<10 \%) \\
\text { - D35 }=\text { M1 with MRD- } \\
\text { PCR }<10^{-3} \text {. }\end{array}$ & $\begin{array}{l}\text { All of the previous criteria. } \\
\text { Rapid responders: } \\
-\mathrm{D} 8<1,000 \text { blasts/ } \mu \mathrm{L} ; \\
-\mathrm{BM} \text { at } \mathrm{D} 15=\mathrm{M} 1 / \mathrm{M} 2 \text { with MRD- } \\
\mathrm{FCM}<10 \% \text {; at } \mathrm{D} 35=\mathrm{M} 1 \text { with } \\
\mathrm{MRD}-\mathrm{PCR}<10^{-3} \text {. } \\
\text { Slow responders: } \\
-\mathrm{D} 8>1,000 \text { blasts } / \mu \mathrm{L} ; \\
-\mathrm{BM} \text { at } \mathrm{D} 15=\mathrm{M} 2 / \mathrm{M} 3 \text { with MRD- } \\
\mathrm{FCM} \geq \mathrm{BM} \\
-\mathrm{D} 35=\mathrm{M} 2 / \mathrm{M} 3 \text { with } \mathrm{MRD}-\mathrm{PCR} \\
\mathrm{PCR} \geq 10^{-3} \text {. }\end{array}$ \\
\hline
\end{tabular}


Silva et al.

Table 1: Continuação

\begin{tabular}{|c|c|c|c|}
\hline \multirow{2}{*}{$\begin{array}{l}\mathrm{NCl} \text { criteria and } \\
\text { treatment regimens }\end{array}$} & \multicolumn{3}{|c|}{ Risk groups } \\
\hline & LR & IR & HR \\
\hline BFM 95 & $\begin{array}{l}\text { - No criteria for high risk; } \\
\text { - Leukocytes < } 20,000 / \mu \mathrm{L} ; \\
\text { - Age at diagnosis between } \\
1 \text { and } 6 \text { years; }\end{array}$ & $\begin{array}{l}\text { - No criteria for high risk; } \\
\text { - And leukocytes } \\
<20,000 / \mu \mathrm{L} ; \\
\text { - And/or age at } \\
\text { diagnosis }<1 \text { year } \\
\text { or } \geq 6 \text { years }\end{array}$ & $\begin{array}{l}\text { - Poor response to corticosteroids; } \\
\text { - And/or no CR at D33 } \\
\text { of induction; } \\
\text { - And/or evidence of } \mathrm{t}(9 ; 22) \\
\text { or BCR-ABL; } \\
\text { - And/or evidence of } \mathrm{t}(4 ; 11) \text { or } \\
\text { MLL-AF4 fusion gene. }\end{array}$ \\
\hline IC-BFM 2002 & 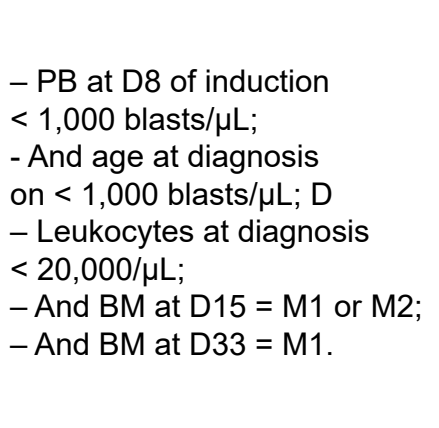 & $\begin{array}{l}-\mathrm{PB} \text { at } \mathrm{D} 8 \text { of } \\
\text { induction }<1,000 \text { blasts } / \mu \mathrm{L} ; \\
\text { - And age at diagnosis } \\
<1 \text { year or } \geq 6 \text { years and/ } \\
\text { or leukocytes at diagnosis } \\
\geq 20,000 / \mu \mathrm{L} ; \\
\text { - BM at } \mathrm{D} 15=\mathrm{M} 1 \text { or } \mathrm{M} 2 ; \\
- \text { And } \mathrm{BM} \text { at } \mathrm{D} 33=\mathrm{M} 1 \text { or } \\
\text { standard risk criteria, but } \\
\mathrm{BM} \text { at } \mathrm{D} 15=\mathrm{M} 3 ; \\
-\mathrm{BM} \text { at } \mathrm{D} 33=\mathrm{M} 1 \text {. }\end{array}$ & $\begin{array}{l}\text { - At least one of the } \\
\text { following criteria: } \\
\text { - IR and BM at D15 = M3 (non- } \\
\text { standard risk and M3 at D15); } \\
\text { - Blasts in PB at D8 } \geq \text { Blasts in } \\
\text { PB at } \\
\text { - BM at D33 = M2 or M3; } \\
\text { - Presence of } t(9 ; 22) \text { or } t(4 ; 11) \\
\text { [MLL-AF4]. }\end{array}$ \\
\hline IC-BFM 2009 & $\begin{array}{l}\text { - PB at D8: }<1,000 \text { blasts } / \mu \mathrm{L} ; \\
\text { - And age } \geq 1 \text { year } \\
\text { and }<6 \text { years; } \\
\text { - And initial } \\
\text { leukocytes }<20,000 / \mu \mathrm{L} ; \\
\text { - And if available: MRD- } \\
\text { FCM }<0.1 \% \text { or M1/M2 BM } \\
\text { at D15; } \\
\text { - And } \mathrm{M} 1 \mathrm{BM} \text { at D33. } \\
\text { - All criteria must be met. }\end{array}$ & $\begin{array}{l}\text { - All patients who are not } \\
\text { stratified as LR or HR. }\end{array}$ & $\begin{array}{l}\text { - IR and, if available: MRD- } \\
\text { FCM } 10 \% \text { or M3 BM at D15; } \\
\text { - LR and, if available: MRD- } \\
\text { FCM > } 10 \% \text {; } \\
\text { - PB at D8 } \geq 1,000 \text { blasts/ } \mu \mathrm{L} ; \\
\text { - M2 or M3 BM at D33; } \\
\text { - Translocation t }(9 ; 22) \text { [BCR- } \\
\text { ABL] or }(4 ; 11) \text { [MLL-AF } 4] ; \\
\text { - Hypodiploidy } \leq \text { ypodiploidy on } \\
\text { - Any one of these criteria is } \\
\text { sufficient to classify as HR. }\end{array}$ \\
\hline
\end{tabular}

BFM: Berlin-Frankfurt-Münster group; BM: bone marrow; CNS: central nervous system; CR: complete remission; D8: day 8 of induction; D15: day 15 of induction; D33: day 33 of induction; FCM: flow cytometry; GBTLI: Brazilian Cooperative Group for the Treatment of Childhood Acute Lymphoblastic Leukemia (Grupo Brasileiro de Tratamento da Leucemia Infantil); HR: high risk; IC: Intercontinental; IR: intermediate risk; LR: low risk; M1: BM blasts < 5\%; M2: BM blasts 5 to < 25\%; M3: BM blasts $\geq 25 \%$; MRD: minimal residual disease; NCl: National Cancer Institute; PB: peripheral blood; PCR: polymerase chain reaction.

Adapted from Smith et al.; Moricke et al.; Stary et al.; Schrappe et al.; Brandalise et al.; Scrideli et al.; Brandalise et al. ${ }^{8-14}$.

Exclusion criteria were patients with missing data for risk stratification or those with non-B-cell ALL.

The study was approved by the Research Ethics Committee (approval number: CAAE 55303916.5.0000.5327).

\section{Data structure and statistical analysis}

Sample size was calculated using WinPepi (v11.43). Based on an expected kappa value of 0.8 , a maximum range of kappa of 0.28 , a significance level of $5 \%$, and a prevalence rate of $47 \%{ }^{16}$, a sample size of 74 patients was required.

Data were entered into an Excel spreadsheet, version 2016, and then exported to SPSS, version 20.0 , for statistical analysis. Data were expressed as absolute or relative frequencies and means, medians, or percentiles. Survival curves were estimated by the Kaplan-Meier method and compared by the log-rank test. Overall survival was measured from the date of the diagnosis of ALL to the date of death or last contact. Event-free survival was measured from the date of the diagnosis of ALL to the date of relapse, refractoriness to treatment, death, or last contact. Refractoriness was defined as the failure to achieve a complete response after regular chemotherapy.

The risk classifications of each protocol were analyzed for agreement using the kappa coefficient, and the results were interpreted according to the different ranges of kappa values suggested by Landis \& Koch $^{17}$. Kappa values $>0.75$ indicate excellent agreement, values $<0.40$ indicate poor agreement, and values between 0.40 and 0.75 indicate fair to good agreement. To calculate the kappa coefficient, 
we excluded the classifications based solely on the $\mathrm{NCl}$ criteria and the classifications based on the GBTLI 99 protocol criteria.

All data were updated to October 2017, and a $p$-value $<0.05$ was considered significant.

\section{RESULTS}

A total of 75 patients aged 1-18 years with a diagnosis of B-ALL were analyzed. Of these, $57.3 \%$ were male. Median age was 5 years; $25 \%$ of children were younger than 3 years, while $25 \%$ were older than 10 years. The main clinical and laboratory characteristics at diagnosis are summarized in Table 2.

Table 2: Clinical and laboratory characteristics and risk group distribution $(\mathrm{N}=75)$.

\begin{tabular}{|c|c|c|}
\hline Characteristics & $\mathbf{n}$ & $\%$ \\
\hline $\begin{array}{l}\text { Age } \\
\text { - Median, years (25th/75th percentile) } \\
\text { - Minimum/maximum }\end{array}$ & $\begin{array}{c}5 \\
(3 / 10) \\
1 / 17\end{array}$ & \\
\hline Male & 43 & 57.3 \\
\hline $\begin{array}{l}\text { Initial leukocyte count }\left(/ \mathrm{mm}^{3}\right) \\
\quad<20,000 \\
20,000 \text { and } 50,000 \\
>50,000\end{array}$ & $\begin{array}{l}39 \\
18 \\
18\end{array}$ & $\begin{array}{l}52 \\
24 \\
24\end{array}$ \\
\hline $\begin{array}{l}\text { CNS } \\
\text { CNS } 1 \\
\text { CNS } 2 \\
\text { CNS } 3\end{array}$ & $\begin{array}{c}66 \\
4 \\
5\end{array}$ & $\begin{array}{l}88 \\
5.3 \\
6.7\end{array}$ \\
\hline $\begin{array}{l}\text { ALL subtypes } \\
\text { Pro-B ALL } \\
\text { Common-B ALL } \\
\text { Pre-B ALL }\end{array}$ & $\begin{array}{c}3 \\
70 \\
2\end{array}$ & $\begin{array}{c}4 \\
93.3 \\
2.7\end{array}$ \\
\hline $\begin{array}{l}\text { Karyotype } \\
\text { Normal } \\
\text { No metaphases growth } \\
\text { Hyperdiploidy } \\
\text { High hyperdiploidy } \\
\text { Low hypodiploidy } \\
\text { Almost diploid } \\
\text { t(1;19)(q23;p13) } \\
\text { t(4;11)(q21;q23) } \\
\text { t(9;22)(q34;q11) } \\
\text { Trisomy } 21 \\
\text { Other changes: } \\
46, X Y,-1,+ \text { mar }[15] \\
46, X X,+1 \text { der(1;16)(q10p10)[20] } \\
46, X X, \text { dup(1)(q21q32)[26] } \\
\text { Data not available }\end{array}$ & $\begin{array}{c}28 \\
12 \\
10 \\
3 \\
1 \\
3 \\
2 \\
1 \\
8 \\
2 \\
3\end{array}$ & \\
\hline
\end{tabular}

Table 2: Continuação

\begin{tabular}{|c|c|c|}
\hline Characteristics & $\mathbf{n}$ & $\%$ \\
\hline $\begin{array}{l}\text { Molecular biology } \\
\text { IKZF1 deletions } \\
\text { TCF3-PBX1 } \\
\text { MLL rearrangement } \\
\text { ETV6-RUNX1 } \\
\text { No molecular changes } \\
\text { No data available }\end{array}$ & $\begin{array}{c}5 \\
1 \\
1 \\
1 \\
45 \\
22\end{array}$ & \\
\hline $\begin{array}{l}\text { Relapse } \\
\text { BM } \\
\text { Testis } \\
\text { CNS } \\
\text { BM + CNS } \\
\text { BM + lymph nodes }\end{array}$ & $\begin{array}{l}16 \\
9 \\
2 \\
2 \\
2 \\
1\end{array}$ & 21.3 \\
\hline $\begin{array}{l}\text { Deaths } \\
\text { Disease } \\
\text { In CR after CT } \\
\text { In CR after BMT }\end{array}$ & $\begin{array}{l}17 \\
9 \\
7 \\
1\end{array}$ & 22.6 \\
\hline $\begin{array}{l}\mathrm{NCl} \text { criteria } \\
\text { LR } \\
\text { HR }\end{array}$ & $\begin{array}{l}44 \\
31\end{array}$ & $\begin{array}{l}58.7 \\
41.3\end{array}$ \\
\hline $\begin{array}{l}\text { GBTLI } 99 \text { classification } \\
\text { LR } \\
\text { HR }\end{array}$ & $\begin{array}{l}37 \\
38\end{array}$ & $\begin{array}{l}49.3 \\
50.7\end{array}$ \\
\hline $\begin{array}{l}\text { GBTLI } 2009 \text { classification } \\
\text { LR } \\
\text { IR } \\
\text { HR }\end{array}$ & $\begin{array}{l}10 \\
24 \\
41\end{array}$ & $\begin{array}{c}13.3 \\
32 \\
54.7\end{array}$ \\
\hline $\begin{array}{l}\text { BFM } 95 \text { classification } \\
\text { LR } \\
\text { IR } \\
\text { HR }\end{array}$ & $\begin{array}{l}23 \\
30 \\
22\end{array}$ & $\begin{array}{c}30.7 \\
40 \\
29.3\end{array}$ \\
\hline $\begin{array}{l}\text { IC-BFM } 2002 \text { classification } \\
\text { LR } \\
\text { IR } \\
\text { HR }\end{array}$ & $\begin{array}{l}21 \\
32 \\
22\end{array}$ & $\begin{array}{c}28 \\
42.7 \\
29.3\end{array}$ \\
\hline $\begin{array}{l}\text { IC-BFM } 2009 \text { classification } \\
\text { LR } \\
\text { IR } \\
\text { HR }\end{array}$ & $\begin{array}{c}8 \\
41 \\
26\end{array}$ & $\begin{array}{l}10.7 \\
54.7 \\
34.7\end{array}$ \\
\hline
\end{tabular}

ALL: acute lymphoblastic leukemia; BFM: Berlin-Frankfurt-Münster group; BM: bone marrow; BMT: bone marrow transplantation; CNS: central nervous system; CR: complete remission; CT: chemotherapy; GBTLI: Brazilian Cooperative Group for the Treatment of Childhood Acute Lymphoblastic Leukemia (Grupo Brasileiro de Tratamento da Leucemia Infantil); HR: high risk; IC: Intercontinental; IR: intermediate risk; LR: low risk; $\mathrm{NCl}$ : National Cancer Institute.

Regarding karyotype, 73 (97.3\%) patients had available information. Of these, $28(38.4 \%)$ had a normal karyotype and $33(45.2 \%)$ had an altered karyotype; in $12(16.4 \%)$ patients, no growth was observed (no metaphases). 
Silva et al.

Of the 75 patients, $53(70.6 \%)$ had access to immunomolecular analysis. In these cases, there were five IKZF1 deletions, one TCF3-PBX1 fusion, one $M L L$ rearrangement, and one ETV6-RUNX1 fusion.

Sixteen $(21.3 \%)$ patients relapsed, and $17(22.6 \%)$ patients died.

Risk classifications were compared between protocols, and agreement was assessed by the kappa coefficient. All kappa values were statistically significant.

There was poor agreement between GBTLI 2009 and BFM 95 protocols (kappa $=0.22 ; p=0.003$ ), and between GBTLI 2009 and IC-BFM 2002 protocols (kappa $=0.24 ; p=0.002$ ). The level of agreement was fair between GBTLI 2009 and IC-BFM 2009 protocols $($ kappa $=0.44 ; p<0.001)($ Table 3$)$.

Table 3: Agreement analysis of risk classifications between GBTLI 2009 and BFM 95; GBTLI 2009 and IC-BFM 2002; GBTLI 2009 and IC-BFM 2009.

\begin{tabular}{|c|c|c|c|c|c|}
\hline & \multicolumn{4}{|c|}{ GBTLI 2009 classification } & \multirow{2}{*}{ Total } \\
\hline & LR & IR & HR & & \\
\hline \multirow{3}{*}{$\begin{array}{l}\text { BFM } 95 \\
\text { classification }\end{array}$} & LR & 7 & 13 & 3 & 23 \\
\hline & IR & 3 & 9 & 18 & 30 \\
\hline & HR & 0 & 2 & 20 & 22 \\
\hline Total & & 10 & 24 & 41 & 75 \\
\hline \multirow{3}{*}{$\begin{array}{l}\text { IC-BFM } 2002 \\
\text { classification }\end{array}$} & LR & 7 & 12 & 2 & 21 \\
\hline & IR & 3 & 10 & 19 & 32 \\
\hline & HR & 0 & 2 & 20 & 22 \\
\hline Total & & 10 & 24 & 41 & 75 \\
\hline \multirow{3}{*}{$\begin{array}{l}\text { IC-BFM } 2009 \\
\text { classification }\end{array}$} & LR & 6 & 2 & 0 & 8 \\
\hline & IR & 4 & 20 & 18 & 42 \\
\hline & HR & 0 & 2 & 23 & 25 \\
\hline Total & & 10 & 24 & 41 & 75 \\
\hline
\end{tabular}

BFM: Berlin-Frankfurt-Münster group; GBTLI: Brazilian Cooperative Group for the Treatment of Childhood Acute Lymphoblastic Leukemia (Grupo Brasileiro de Tratamento da Leucemia Infantil); HR: high risk; IC: Intercontinental; IR: intermediate risk; LR: low risk.

There was better agreement between risk stratification by IC-BFM 2009 and BFM 95 protocols, and between risk stratification by IC-BFM 2009 and IC-BFM 2002 protocols. The kappa coefficient was $0.67(p<0.001)$ and $0.68(p<0.001)$, respectively.

There was an association between risk group and death in cases stratified as high risk, regardless of the treatment protocol used. The percentage of deaths in patients classified as high risk according to the risk classifications of GBTLI 99, GBTLI 2009, BFM 95, IC-BFM 2002, and IC-BFM 2009 protocols was $39.5 \%$ ( $p=0.003$; chi-square test), $36.6 \%$ $(p=0.013$; chi-square test), $54.5 \%(p<0.001$; chisquare test), $54.5 \%$ ( $p<0.001$; chi-square test), and $48.0 \%$ ( $p=0.001$; chi-square test), respectively. There was also a significant association between high risk and relapse: GBTLI 2009, 29.3\% ( $p=0.03$; chisquare test); and IC-BFM 2002, 45.5\% ( $p=0.003$; chi-square test).

The 4-year overall survival was $68.6 \%$, regardless of the treatment protocol used. Mean overall survival was 45.2 months (standard error, 2.2 months). The 4-year event-free survival was $66.6 \%$. Mean event-free survival was 44.7 months (standard error, 2.2 months) (Figure 1).

A

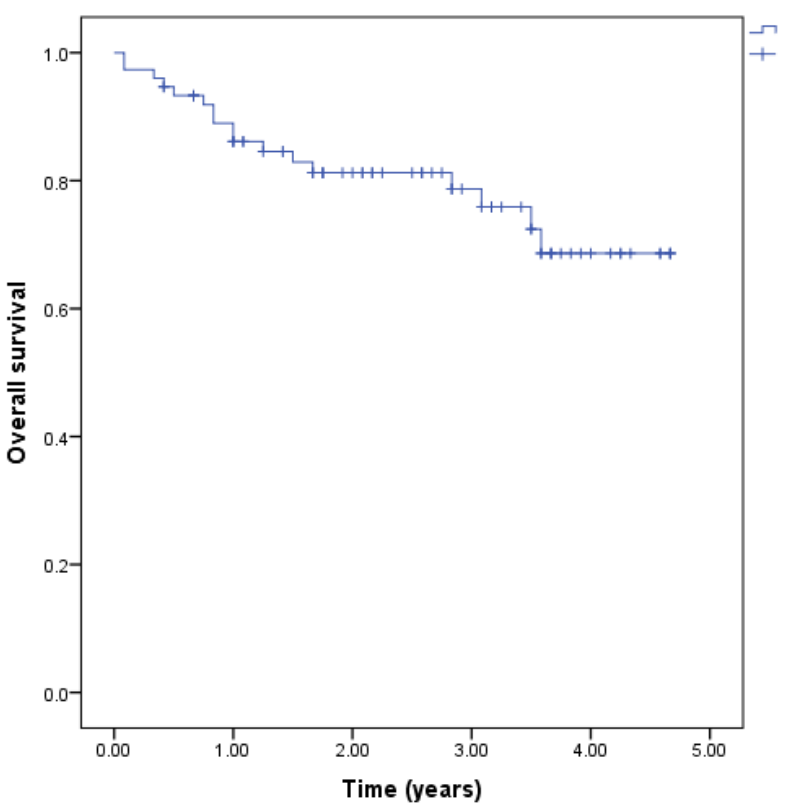

B

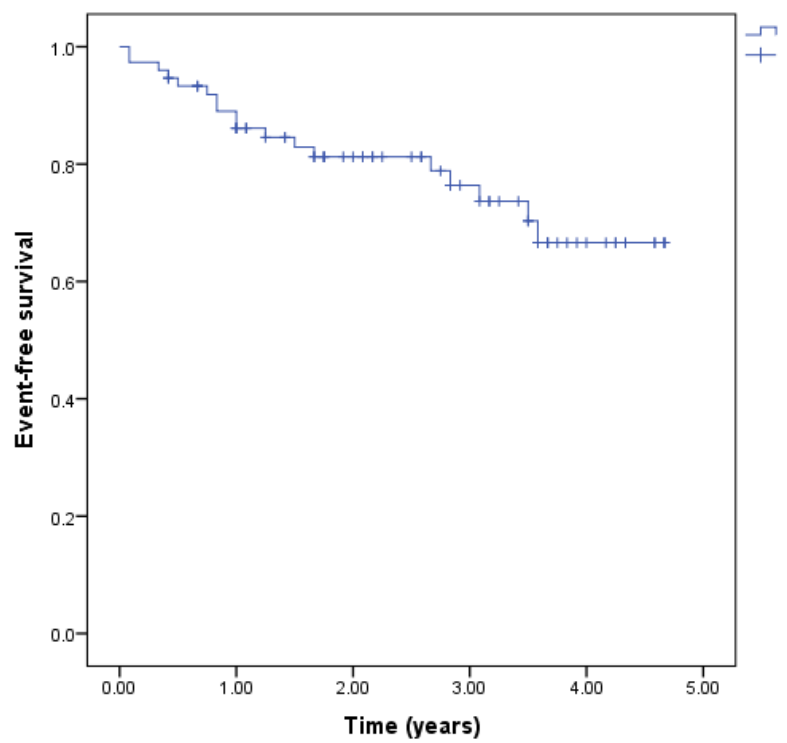

Figure 1: A: Estimated overall survival and; B: estimated event-free survival of the 75 patients, regardless of protocol. 


\section{DISCUSSION}

Our results show that, as expected, there was better agreement between risk classifications of the BFM group, achieving substantial agreement, or nearly excellent agreement, according to the interpretation proposed by Landis \& $\mathrm{Koch}^{17}$. When risk stratification was compared between BFM and GBTLI protocols, the main differences were age and leukocyte count at diagnosis.

Age $\geq 9$ years, leukocyte count $\geq 50,000 / \mathrm{mm}^{3}$, and CNS involvement at diagnosis are considered highrisk features by the Brazilian protocols, regardless of the response to induction therapy ${ }^{15}$. In the BFM protocols, however, patients aged $\geq 6$ years or with leukocyte count $\geq 20,000 / \mathrm{mm}^{3}$ are initially classified as intermediate risk in the absence of high-risk cytogenetic and molecular abnormalities, and these patients may be transferred to the high-risk group, depending on their response to induction therapy. CNS involvement does not change the initial risk stratification ${ }^{11}$. This may explain why, as demonstrated in the present study, the Brazilian protocols tend to have a higher percentage of patients classified as high risk (Table 2).

Agreement was only moderate between risk stratification by the GBTLI 2009 and IC-BFM 2009 protocols, although both protocols have already incorporated the concept of MRD into their risk classification systems. A possible explanation is that MRD is assessed somewhat differently in these protocols. While IC-BFM 2009 considers MRD only at D15 of induction by FCM, GBTLI 2009 considers MRD at $\mathrm{D} 15$ by FCM and MRD at D35 by polymerase chain reaction $(P C R)^{12,15}$. However, in the present study, MRD was assessed only by FCM in all patients, because the hospital does not have appropriate technology for detecting MRD by PCR.

When the risk group distribution of our patients, based on the GBTLI 2009, IC-BFM 2002 and IC-BFM 2009 protocols, was compared with the risk group distribution published in the literature, we found a higher percentage of high-risk patients $(54.7 \%, 29.3 \%$, and $34.7 \%$, respectively, vs. $16.7 \%$ in the literature). Furthermore, a lower percentage of low-risk patients was observed using the risk classifications of the GBTLI 2009 and IC-BFM 2009 protocols $(13.3 \%$ and $10.7 \%$, respectively, vs. $30.9 \%$ in the literature $)^{10,11,18}$.

The 4-year overall and event-free survival rates were $68.6 \%$ and $66.6 \%$, respectively. These rates are lower than recent international rates from clinical trials conducted in North America and Western Europe, which have reported event-free survival rates of up to $85 \%$ and overall survival rates of up to $90 \%{ }^{19}$. Some studies have even reported survival rates above $90 \%$ for some specific subtypes treated with risk-adapted therapy in B-ALL ${ }^{20}$.

In sum, the analysis of the present data showed that there was a difference in risk stratification depending on the treatment protocol or regimen used in our institution. This difference, however, had no impact on the overall survival of affected children.

This study provides numerous points to ponder about the treatment of leukemia in our context. The percentage of patients classified as high risk in our sample was higher than that reported in the international literature. In addition, although the patients were treated in a referral hospital in southern Brazil, which has specialized cancer treatment teams and appropriate resources to ensure supportive care for patients, survival rates were lower than those reported in the literature. However, we must consider that this center receives patients with serious clinical presentation and worse prognosis more frequently, due to the high specialized team. This may also have contributed to the finding of a greater number of patients classified as high risk. These data may also be related to the lower survival rate.

Furthermore, the present study raises some questions for future research: would study findings result from a difference in the Brazilian pediatric population with ALL? Are there regional variations in the presentation of childhoodleukemia in Brazil? Is there a genetic or molecular alteration more prevalent among Brazilians that should be better studied in a larger sample of patients?

Therefore, further prospective laboratory and clinical studies are needed to explore the reasons underlying these differences, and whether they are sensitive to population or sample size, and to investigate the impact of risk stratification on toxicity and cure rates in our.

New approaches should probably improve diagnosis, prognosis and precision medicine in our population. For example, a study of genomic sequencing would allow the identification of subtypes and genetic alterations with prognostic importance and of their potential role in risk stratification ${ }^{21}$. These questions need to be better explored in our context in larger multicenter studies.

\section{Data statement}

All relevant data are within the paper and its Supporting Information files. 


\section{REFERENCES}

1. Belson M, Kingsley B, Holmes A. Risk factors for acute leukemia in children: a review. Environ Health Perspect. 2007;115(1):138-45.

2. Smith MA, Altekruse SF, Adamson PC, Reaman GH, Seibel NL. Declining childhood and adolescent cancer mortality. Cancer. 2014;120(16):2497-506.

3. Howlader N, Noone AM, Krapcho M, Miller D, Bishop K, Altekruse SF, et al. SEER Cancer Statistics Review [Internet]. 1975-2013 [cited on 2018 Mar 14]. Available from: https://seer. cancer.gov/archive/csr/1975_2013/.

4. Karol SE, Pui CH. Personalized therapy in pediatric high-risk B-cell acute lymphoblastic leukemia. Ther Adv Hematol. 2020;11:2040620720927575.

5. Hunger SP, Loh ML, Whitlock JA, Winick NJ, Carroll WL, Devidas M, et al. Children's Oncology Group's 2013 blueprint for research: acute lymphoblastic leukemia. Pediatr Blood Cancer. 2013;60(6):957-63.

6. Vrooman LM, Silverman LB. Childhood acute lymphoblastic leukemia: update on prognostic factors. Curr Opin Pediatr. 2009;21(1):1-8.

7. Borowitz MJ, Devidas M, Hunger SP, Bowman WP, Carroll AJ, Carroll WL, et al. Clinical significance of minimal residual disease in childhood acute lymphoblastic leukemia and its relationship to other prognostic factors: a Children's Oncology Group study. Blood. 2008;111(12):5477-85.

8. Stow P, Key L, Chen X, Pan Q, Neale GA, Coustan-Smith E, et al. Clinical significance of low levels of minimal residual disease at the end of remission induction therapy in childhood acute lymphoblastic leukemia. Blood. 2010;115(23):4657-63.
9. Smith M, Arthur D, Camitta B, Carroll AJ, Crist W, Gaynon P, et al. Uniform approach to risk classification and treatment assignment for children with acute lymphoblastic leukemia. J Clin Oncol. 1996;14(1):18-24.

10. Moricke A, Reiter A, Zimmermann M, Gadner H, Stanulla M, Dordelmann M, et al. Risk-adjusted therapy of acute lymphoblastic leukemia can decrease treatment burden and improve survival: treatment results of 2169 unselected pediatric and adolescent patients enrolled in the trial ALL-BFM 95. Blood. 2008;111(9):4477-89.

11. Stary J, Zimmermann M, Campbell M, Castillo L, Dibar E, Donska S, et al. Intensive chemotherapy for childhood acute lymphoblastic leukemia: results of the randomized intercontinental trial ALL IC-BFM 2002. J Clin Oncol. 2014;32(3):174-84.

12. Campbell $M$, Castillo $L$, Riccheri $C$ Janic $D$, Jazbec J, Bratislava EK, et al. ALL IC-BFM 2009: a randomized trial of the I-BFM-SG for the management of childhood acute lymphoblastic leukemia. final version of therapy protocol. Germany: [publisher unknown]; 2009.

13. Brandalise SR, Pinheiro VR, Aguiar SS, Matsuda El, Otubo R, Yunes JA, et al. Benefits of the intermittent use of 6-mercaptopurine and methotrexate in maintenance treatment for low-risk acute lymphoblastic leukemia in children: randomized trial from the Brazilian Childhood Cooperative Groupprotocol ALL-99. J Clin Oncol. 2010;28(11):1911-8.

14. Scrideli CA, Assumpção JG, Ganazza MA, Araujo M, Toledo SR, Lee MLM, et al. A simplified minimal residual disease polymerase chain reaction method at early treatment points can stratify children with acute lymphoblastic leukemia into good and poor outcome groups. Haematologica. 2009;94(6):781-9.

15. Brandalise SR, Pinheiro VR, Lee MLM, Toledo S, Delbuno E, Oliveira MSP, et al. Protocolo de tratamento da leucemia linfoblástica aguda da criança e do adolescente - GBTLI LLA - 2009.

Brazil: [publisher unknown]; 2009.

16. Basso G, Veltroni M, Valsecchi MG, Dworzak MN, Ratei R, Silvestri $D$, et al. Risk of relapse of childhood acute lymphoblastic leukemia is predicted by flow cytometric measurement of residual disease on day 15 bone marrow. J Clin Oncol. 2009;27(31):5168-74.

17. Landis JR, Koch GG.

The measurement of observer agreement for categorical data. Biometrics. 1977;33(1):159-74.

18. Conter V, Bartram CR, Valsecchi MG, Schrauder A, Panzer-Grumayer R, Moricke A, et al. Molecular response to treatment redefines all prognostic factors in children and adolescents with B-cell precursor acute lymphoblastic leukemia: results in 3184 patients of the AIEOP-BFM ALL 2000 study. Blood. 2010;115(16):3206-14.

19. Hunger SP, Mullighan CG. Acute lymphoblastic leukemia in children. N Engl J Med. 2015;373(16):1541-52.

20. Pui $\mathrm{CH}$, Pei D, Raimondi SC, Coustan-Smith E, Jeha S Cheng $C$, et al. Clinical impact of minimal residual disease in children with different subtypes of acute lymphoblastic leukemia treated with Response-Adapted therapy. Leukemia. 2017;31(2):333-9.

21. Hunger SP, Mullighan CG. Redefining ALL classification: toward detecting high-risk ALL and implementing precision medicine. Blood. 2015;125(26):3977-87. 